\title{
Environmental competitiveness of Hai Duong tourism destination
}

\author{
Xuan Tung Nguyen ${ }^{1, *}$ \\ ${ }^{1}$ Institute of Southeast Asian studies, Vietnam Academy of Social Sciences, no.1 Lieu Giai str., Ba \\ Dinh district, Hanoi, 10000, Vietnam
}

\begin{abstract}
Located in the northern economic focal region, Hai Duong is one of the cultural and spiritual centers of Vietnam. Hai Duong is not only favored with beautiful natural sceneries such as Con Son, Kiep Bac, Kinh $\mathrm{Chu}, \mathrm{An} \mathrm{Phu}, \ldots$ but it also owns priceless cultural and historical assets such as traditional festivals, historical relics, and folk songs, etc... This diversity allows Hai Duong to develop different types of eco-tourism. However, there are many hinderances to Hai Duong in making tourism the key economic sector. The province has failed to determine its own direction of tourism development, leading to ineffective investment in tourist attraction sites. Insufficient promotion of local tourist attractions also make the tourism products offered non-unique. These problems reduce destination competitiveness of the province. Based on theories of destination competitiveness, this article evaluated the current status of tourism destination competitiveness in Hai Duong province on a number of criteria, then suggesting recommendations, solutions to improve the competitiveness of the province in the new development period.
\end{abstract}

\section{Introduction}

Located in the northern economic focal region, Hai Duong is one of the cultural and spiritual centers of Vietnam. Hai Duong is not only favored with beautiful natural sceneries such as Con Son, Kiep Bac, Kinh Chu, An Phu, ... but it also owns priceless cultural and historical assets such as traditional festivals, historical relics, and folk songs, etc... This diversity allows Hai Duong to develop different types of eco-tourism.

However, there are many hinderances to Hai Duong in making tourism the key economic sector. The province has failed to determine its own direction of tourism development, leading to ineffective investment in tourist attraction sites. Insufficient promotion of local tourist attractions also make the tourism products offered non-unique. These problems reduce destination competitiveness of the province.

Rapid global changes and the outbreak of the COVID-19 pandemic have raised the question: How to improve the competitiveness of Hai Duong tourism in the new period? In this article, we relied on theories about destination competitiveness to assesse destination competitivenes of Hai Duong tourism, thereby proposed recommendations for improving local tourism.

\footnotetext{
*Corresponding author: xuantung23992@gmail.com
} 
Tourism competitiveness have attracted research by both international and Vietnamese authors. Most notable researchers that have conceptualized destination competitiveness are Michael Porter, Ritchie and Crouch, Dwyer and Kim,... Michael Porter proposed a fourfactor model (conditions of production and service factors; related supporting industries; demand conditions; industry strategy, structure and competition) that affect competitiveness of a particular country or locality. These factors interact with each other and form the competitiveness of a country.

Based on the work of M. Porter, Ritchie and Crouch developed the competitive capacity theory model, which later became highly popular among authors in the field. In this model, comparative advantage creates tourism resources available at the destination, where competitiveness is the ability to use that resource efficiently during long periods. The key factors in the destination are not just necessary to create comparative advantage and competitiveness, not just the basic resource that generates the incentives for destination choices, but also the important factor that strategic planners need to consider. On the other hand, this model specifies the components of destination competitiveness: (i) destination policy, planning and development; (ii) qualifying and amplifying determinants; (iii) destination management, (iv) core resources and attractions, and (v) support and resources.

Another model developed from Porter's is Dwyer and Kim's model of destination competitiveness assessment. Destination competitiveness is price differences and changes in exchange rates, productivity levels of the components of the tourism industry and quality factors that influence the attractiveness of a destination. This model shows factors affecting competitiveness of the destination including: Artificial resources (infrastructure, events); Inherited resources (mountains, seas, lakes, landscapes); Supporting resources (accessibility, quality of service); Manage destinations; Development Policies and Demand Factor. The model also shows that the resource and destination management factors interact with tourism demand to affect destination competitiveness and socio-economic prosperity.

The World Travel and Tourism Council (WTTC) and the World Economic Forum (WEF) have used a set of indicators to assess the competitiveness of the tourism industry including 8 main indicators such as: i) tourism human resources; ii) price competitiveness index; iii) Infrastructure development index; iv) Environment index; v) Technology progress index; vi) Human resource index; vii) openness and viii) Social Development Index. In which, only the price index and environmental indicators will be used in the evaluation of resource use, the remaining 6 indicators can be used to assess the comparative advantage of the tourism sector in the region. Since 2007, WEF announced the assessment of country's tourism competitiveness. This is an important source of information that helps researchers, managers find out and evaluate the competitiveness of tourism destinations in the world.

In this paper, we relied on Dwyer and Kim's model on tourism destination competition, combined with local development, based on a number of criteria such as: inherited resources; artificial resources; supporting resources and development policies to assess the competitiveness of Hai Duong's tourism destinations.

\section{Materials and methods}

Rapid global changes and the outbreak of the COVID-19 pandemic have raised the question: How to improve the competitiveness of Hai Duong tourism in the new period? In this article, we relied on theories about destination competitiveness to assesse destination competitivenes of Hai Duong tourism, thereby proposed recommendations for improving local tourism. We relied on Dwyer and Kim's model on tourism destination competition, combined with local development, based on a number of criteria such as: inherited resources; artificial resources; supporting resources and development policies to assess the 
competitiveness of Hai Duong's tourism destinations.

\section{Results}

\subsection{Destination competitiveness of Hai Duong tourism}

In terms of natural conditions, Hai Duong is a locality with both plains and hills, which is the basis for diversified and vigorous development of agricultural and forestry products. The river system is quite dense, including the system of Thai Binh, Luoc and Bac Hung Hai axes capable of compensating alluvium for fields, and also a waterway, creating good conditions for the goods exchange within the province as well as with other provinces in the region. Hai Duong is located in a tropical monsoon zone, hot and humid, characterized by tropical climate, monsoon and has all four seasons. This is the favorable weather for human living environment, the development of flora and fauna and suitable for tourism activities. In particular, the climatic conditions in winter are very favorable for the development of food crops, especially the ability to grow vegetables for export.

With prominent advantages of geographical locations, natural conditions, Hai Duong is always the destination that attracts the most tourists in the northern region. Its neighbouring provinces like Ha Noi, Hai Phong, Quang Ninh create favorable conditions in connection, exchange, and exchange of goods, technology and tourism development.

However, due to the lack of master planning in economic development in the region, the effectiveness of the ecosystem is low. Deforestation in the upstream, inappropriate use of pesticides and chemical fertilizers in the cultivation process, rapid industrialization and urbanization and increased waste have greatly affected the environment and destroyed the ecosystem balance of Hai Duong province.

On the technical infrastructure, the accommodation system in Hai Duong province has been constantly strengthened during the 2016 - 19 period. Particularly, in 2016, the province has over 140 accommodation facilities, with more than 3, 000 rooms, including 1 hotel class 4, 2 hotels class 3, 15 hotels class 2 and 5 hotels class 1, the rest are motels; By 2019 , the corresponding number is over 160 accommodation establishments, with over 4,650 rooms, including 1 hotel class 4, 2 hotels class 3, 17 hotels class 2 and 6 hotels class 1 , the rest are motels. The capacity of the use of rooms, the average room is estimated to be $60 \%$; the duration of accommodation of the short and average visitor is only about 1,9 days per visitor. The total number of workers in the accommodation sector is around 1.500 people. Although Hai Duong's tourist accommodation facility has increased but most accommodation establishments owned by the private sector $(77 \%)$, the rest are in the state sector; the use of low - accommodation facilities, which are not balanced between the demand, in which the main reason is due to lack of planning and mass building.

On transport vehicles, the province currently has about 30 enterprises and some business households transporting tourists with the total number of more than 800 vehicles. Most of the transport means are upgraded or refurbished, ensuring polite, safe and safe. In general, the type of travel of tourism meets standards of quality, experienced drivers of experience and convenience. However, drivers are limited in services and foreign languages.

For entertainment entertainment, despite the potential in this field, it has not been implemented properly. Nowadays, Hai Duong has a golf course; services such as massage massage rooms, karaoke rooms, tennis courts are mainly serving domestic visitors. Other facilities like swimming pools, nightclubs and other entertainment activities are barely developed.

Tourism infrastructure is not eligible for the organization of tourism such as group 
tourism, experience tourism, ... as well as large-scale entertainment and high-level entertainment zones to meet international demands. Most of the projects are not large and do not create any breakthroughs (There' s no President Room in hotel, the suite has limited number). This is the limited factor of attracting tourists as well as organizing workshops, international conferences, areas.

To promote tourism promotion has been promoted, promoting promotion activities such as workshops, working with central ministries, branches and localities, the enterprises in and outside the province to propagate provincial - level policies, encourage organizations and individuals to invest in tourism business. For example, in 2019, Hai Duong organized 2 big programs to promote tourism, one of which is the Hai Duong tourism beauty photo contest, with nearly 400 works participating in the contest - this is a repository of documents. to promote tourism effectively ... Coordinate with Vietnam Television Station to build and broadcast 4 reportages promoting local attractions and $6 \mathrm{TV}$ programs promoting tourism, di historical, cultural, culinary, and trade village of Hai Duong; coordinated with Hai Duong Radio - Television to implement the program "Discover Hai Duong" (Hai Duong Department of Culture, Sports and Tourism (2019), Report on tourism activities in 2019 and orientation and key tasks in 2020)...

Regarding the number of tourists, in the period of 2016 - 2019, with many efforts in improving service quality, building a civilized tourism environment, bringing high satisfaction to tourists by focusing on upgrading tourism service infrastructure, promoting tourism, strictly controlling market prices,... contribute to attracting the number of tourists coming to this locality to increase rapidly. As of 2019, there are about 4,295,000 visitors, up $8.73 \%$ over the same period in 2018; of which 1,5250,000 arrivals, an increase of $6.64 \%$ over the same period in 2018 (of which international visitors reached 315,000 arrivals, domestic visitors reached 1,210,000); Non-residents: 2,770,000 arrivals, up 9.92\% over the same period in 2018 (Hai Duong Department of Culture, Sports and Tourism (2019), Report on tourism activities in 2019 and orientation and key tasks in 2020.). Although the number of tourists coming to Hai Duong is large, the number of tourists who choose stays overnight is low and the ratio of staying tourists to the total number of tourists is decreasing. Tourism revenue in 2019 reached 1,980 billion VND, an increase of $10 \%$ over the same period (Figure 1).

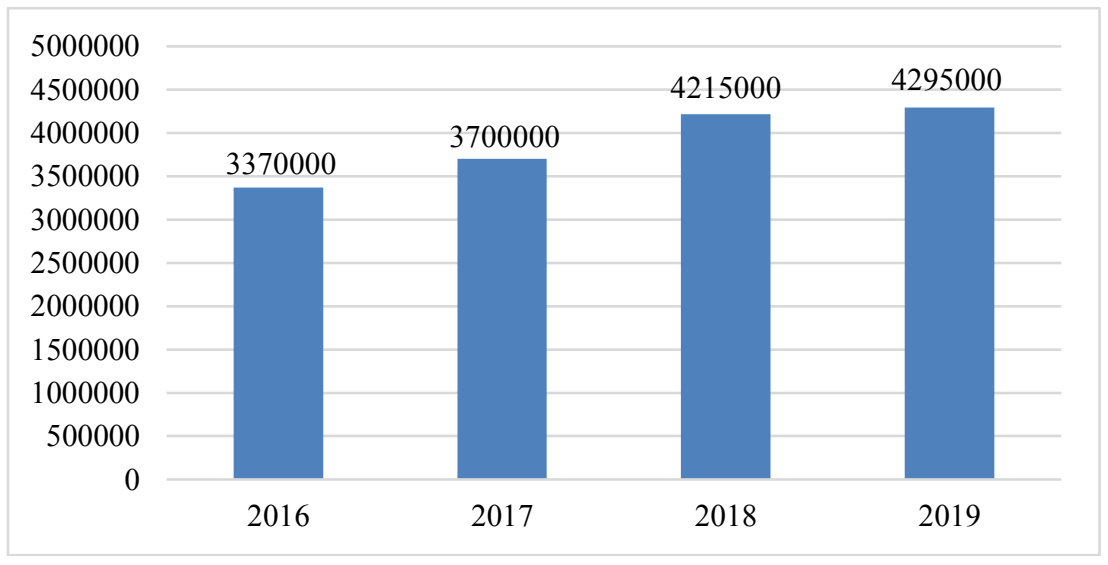

Fig. 1. Number of tourists to Hai Duong in the period of 2016 - 2019 (Source: The author selfsynthesized).

Beside, the number of international visitors in the 2016 - 2019 also increased sharply. In 2019, international visitors will reach 1,350,000 domestic visitors will reach 1,420,000. Due to the geographical features and advantages, in addition to the growth in the number of 
accommodation guests, the number of tourists coming to Hai Duong who do not use accommodation services also increased rapidly. This is a distinctive of Hai Duong tourism, significantly affecting local tourism business results. The percentage of international tourists out of the total number of tourists to Hai Duong is quite stable and accounts for around $20 \%$ with an average growth rate of over $18.5 \%$ per year. But the average date of stay for international tourists to Hai Duong is limited and lower than the national average. Thus, the proportion of international tourists to Hai Duong is quite good, but compared to many localities in the northern key economic region, this number of tourists is still low compared to the location and tourism potential local (Figure 2).

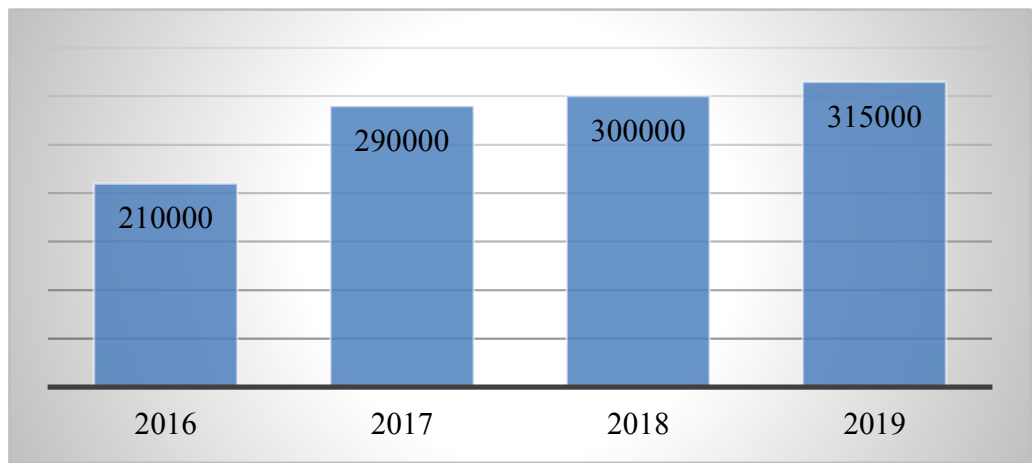

Fig. 2. Number of international visitors to Hai Duong from 2016 to 2019 (Source: The author selfsynthesized).

Generally, in 2016 - 2019, Hai Duong tourism has a growth in both the number of tourists and tourism facilities, creating a large source of revenue for the local budget. If in 2016 , tourism revenue was only 1,482 billion VND, by 2019 , this number was 1,980 billion VND (Figure 3).

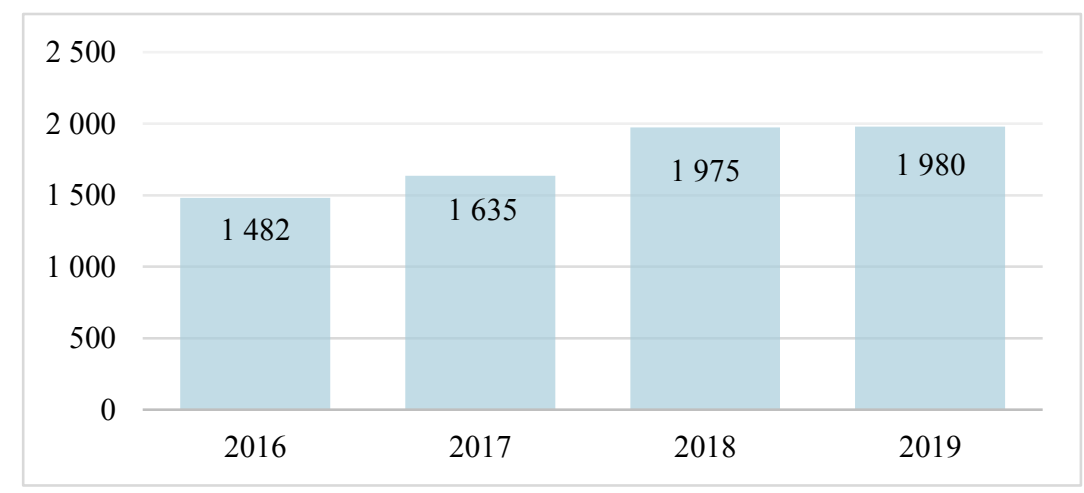

Fig. 3. Tourism revenue of Hai Duong in the period of 2016 - 2019. Unit: Billion VND (Source: The author self-synthesized).

In addition, the complicated developments of the Covid-19 pandemic from the beginning of 2020 to now show enormous impacts on tourism, especially on the competitiveness of tourism destinations on a global scale. each country and Hai Duong is no exception. According to experts, the tourism industry experienced the most difficult period since 1950 onwards. Tourism has been hit hardest of all, as countries close their borders and people have limited travel. The number of international tourists to Vietnam in general and to Hai Duong in particular has decreased sharply. The number of domestic tourists is also in a similar situation, estimated to have decreased by $75-85 \%$, corresponding 
to a drop in export revenue from tourism and placing thousands of jobs directly related to tourism at risk.

Hai Duong has researched and issued many policies which is including adjust the master plan for tourism development in Hai Duong province to 2020, researching and building tourism product models in Hai Duong province in the period of $2016-2020$,... At the same time, directing the construction and approval of the tourism promotion program in Hai Duong province as well as building a model of community based tourism development on Co Chi Lang Nam island. Besides, continue to improve mechanisms and policies, strengthen the state management capacity on tourism. Hai Duong approves investment incentives, builds financial regimes and enhances service quality management. This locality renovates and upgrades infrastructure and builds tourism products. Because of the shortage of tourism human resources, the local government has implemented a policy of training and retraining to improve the quality of human resources by organizing training and retraining classes as well as Priority mechanism helps tourism businesses to invest in improving the quality of the tourism workforce.

However, up to now, there has not been concretization of mechanisms and policies suitable to reality so there is no key tourism product; characteristics of the destination have not been clearly formed; tourism infrastructure develops slowly, lacks of synchronization; human resource is still poor in quantity and quality.

- In addition, the complicated developments of the Covid 19 pandemic from the beginning of 2020 up to now show enormous impacts on tourism, especially on the competitiveness of tourism destinations on a global scale. each country and Hai Duong is not an exception. According to experts, the tourism industry experienced the most difficult period since 1950 onwards. Tourism has been hit hardest of all, as countries close their borders and people have limited travel. The number of international tourists to Vietnam in general and to Hai Duong in particular has decreased sharply. The number of domestic tourists is also in a similar situation, estimated to have decreased by $75-85 \%$, corresponding to a drop in export revenue from tourism and placing thousands of jobs directly related to tourism at risk.

\section{Conclusion and recommendations}

Although there are many potentials to develop the tourism, Hai Duong's the tourism destination is not really commensurate with the potentials, advantages of natural conditions, geographical location and tourism resources. existing documents, still have some limitations and shortcomings that deserve attention. Therefore, some recommendations can be made to improve the competitiveness of tourism destinations in Hai Duong province in the coming time as follows:

- Planning and implement a strategy to enhance tourism development with a focus on linking the development of the tourism value chain of Hai Duong with neighboring localities to diversify and improve the quality of tourism products, related services with high added value to meet the needs of the target markets, thereby enhancing destination competitiveness, attracting tourists and business efficiency.

- Review the planning of tourist destinations in Hai Duong in accordance with the domestic or international market orientation for each destination and tourist area to have a reasonable development plan. To be more specific, researching and promulgating specific local mechanisms and policies to attract investment in tourism development in the locality, with priority given to attracting qualified and experienced enterprises.

- Build the infrastructure routes, potential tourist spots; upgrade tourism infrastructure connecting Hai Duong with potential tourist destinations in the vicinity to ensure a diversified and attractive tourism product system. To attach importance to integrating 
tourist attractions and tourist facilities and technical facilities (hotels, restaurants, souvenir shops, etc.); Coordinate with travel businesses to organize tours, routes suitable to attract domestic and international tourists - based on customs and habits and income of each type of tourists; Develop eco-tourism programs in association with rural areas; support to restore the development of traditional craft villages (with tourism products such as embroidery, lace, gold and silver, carving, etc.), contributing to diversifying tourism products.

- Promote the linkage of tourism development between Hai Duong and destinations in the vicinity - with the nature of an economic sector of interdisciplinary, inter-regional and highly socialized, tourism development is not just in one territory. territories that always extend out of the administrative scope of a locality, a country, a region. It should be noted that Hai Duong is located on the axis of Hanoi - Hai Phong - Quang Ninh, so attracting tourists is a very difficult problem, so it is necessary to promote links to develop suitable tourism products, especially products. 'unique' tourism, such as organizing a 'night economy' and other community cultural activities aimed at attracting overnight tourists with 'unique' tourism products by Hai Duong.

- Branding and promotion of tourist destinations in Hai Duong province; Link training and development of tourism human resources, develop an attractive incentive mechanism to seek and attract talents to serve local tourism, especially those who have been trained in tourism in countries with developed tourism.

- Monitoring developments of epidemics, especially Covid-19 in the world and in the country. It is necessary to develop a response scenario in a timely and appropriate manner to create jobs, protect livelihoods and continue to play an important role. important in promoting sustainable development. Focus on reviewing tourist destinations, reassessing all tourism activities (hotels, travel...) in Hai Duong before and during the epidemic; Tourism businesses actively upgrade and embellish technical facilities to serve tourists; Focus on improving the quality of tourism products and services, innovating and diversifying products, creating new products and services; Organize sanitation activities, protect the environment at tourist destinations, tourist service providers, and areas where tourists are concentrated.

\section{References}

1. Ch. Kim, L. Dwyer, Current Issues in Tourism 6(5), 369-414 (2003)

2. G.I. Crouch, J.R.B. Ritchie, The Competitive Destination: A sustainable tourism perspective (CAB, Wallingingford, 2000)

3. L.N. Thuc, T.V. Hoa, Economic Development and Prospects in the ASEAN (Palgrave Macmillan, London, 1997) https://doi.org/10.1007/978-1-349-25921-2_6

4. Reporting the results of tourism activities for the years 2016 - 2019 (Hai Duong Department of Culture, Sports and Tourism, Hai Duong, 2019)

5. L. Dwyer, R. Mellor, Z. Livaic, D. Edwards, Ch. Kim, Tourism analysis 9(1/2), 91-101 (2004)

6. M.E. Porter, M. Delgado, Ch. Ketels, S. Stern, The determinants of National competitiveness, NBER working paper no. 18249 (2012)

7. L. Bui, Archival Others: The Vietnamese as Absent Presence in the Historical Record. In Returns of War: South Vietnam and the Price of Refugee Memory (NYU Press, New York, 2018) http://www.jstor.org/stable/j.ctvwrm5fh.5.

8. N. Avieli, Sojourn: Journal of Social Issues in Southeast Asia 30(1), 35-71 (2015) http://www.jstor.org/stable/24779829 